\title{
Type IVA choledochal cyst: a rare cause of cirrhosis in adults
}

\author{
Chantelli lamblaudiot Razafindrazoto ${ }^{1 *}$ (D), Andry Lalaina Rinà Rakotozafindrabe ${ }^{1}$ \\ Sakaiza Malala Randrianambininjanahary², Nitah Harivony Randriamifidy?', \\ Domoina Harivonjy Hasina Laingonirina', Sonny Maherison', Lova Hasina Ny Ony Narindra Rajaonarison², \\ Tovo Harimanana Rabenjanahary', Soloniaina Hélio Razafimahefa ${ }^{3}$ and Rado Manitrala Ramanampamonjy ${ }^{1}$
}

\begin{abstract}
Background: Choledochal cysts (CDCs) are characterized by congenital cystic dilations of the intrahepatic or extrahepatic bile ducts or both. CDCs are very rarely reported in sub-Saharan Africa. This congenital anomaly of the bile ducts is rarely discovered at the stage of advanced chronic liver disease with portal hypertension. We report the first Malagasy case of a type IVA choledochal cyst discovered during an etiological work-up of cirrhosis.
\end{abstract}

Case presentation: A 23-year-old woman was hospitalized for jaundice and ascites. Biological and radiological investigations have led to the diagnosis of secondary biliary cirrhosis due to type IVA choledochal cyst. In view of the severity of the liver damage (Child-Pugh C score), a collegial decision (hepato-gastroenterologists and visceral surgeons) had rejected surgical intervention and opted only for the management of cirrhotic decompensation.

Conclusion: A type IVA choledochal cyst is a possible etiology of advanced chronic liver disease.

Keywords: Choledochal cyst, Cirrhosis, adults, Madagascar, Case report

\section{Background}

Choledochal cysts (CDCs) are rare diseases of the bile ducts, characterized by congenital cystic dilation of the intrahepatic or extrahepatic bile ducts or both [1]. Globally, they are uncommon in the West and more common in East Asia [2, 3]. The incidence of CDCs ranges from 1 in 100,000 to 1 in 150,000 individuals in Western countries to 1 in 13,000 individuals in Japan [1]. Alonso-Lej had first classified choledochal cysts in 1959, and Todani updated the classification system in 1977 by dividing choledochal cysts into 5 types $[4,5]$ : type I $(80-90 \%$ of all CDCs), type II ( $2 \%$ of reported cases), type III (1-4\% of CDCs), type IV (15-20\%), and type V or Caroli disease (10\%) [1-6]. Type IVA cysts are multiple intrahepatic

\footnotetext{
*Correspondence: iamblaudiotchantelli@yahoo.com; chantelliri@gmail.com

1 Unity of Gastroenterology, University Hospital Joseph Raseta

Befelatanana, Antananarivo, Madagascar

Full list of author information is available at the end of the article
}

and extrahepatic dilations. The dilation of the intrahepatic duct may be cystic, fusiform, or irregular [1-7]. The etiology of these cysts remains unknown, but they are considered congenital as approximately $75 \%$ of cases are observed in children under 10 years of age. They are rare in adulthood and more frequent in females $(1 \mathrm{male} / 4$ females) [1-6]. CDCs are most often associated with hepatobiliary complications. Cirrhosis with portal hypertension (PHT) is one of the rare complications [5]. The problems of management of patients with CDCs and cirrhosis are generally not well addressed, due to their low incidence and the variability of the underlying causes of PHT [5]. We report the first Malagasy case of choledochal cyst (CDC) at the stage of secondary biliary cirrhosis (SBC) with portal hypertension. 


\section{Case presentation}

A 23-year-old woman presented at August 162021 with large ascites, jaundice, and dark urine since March 2021. She has no history of alcohol consumption or hepatotoxic medications. She had a history of jaundice at the age of 6 years. The patient reported amenorrhea since February 2021. The clinical examination at admission showed splenomegaly, ascites with abdominal collateral venous circulation, a hard, poorly limited, painless epigastric mass, and bilateral lower limb edema. She had no signs of hepatic encephalopathy. We noted an absence of signs of heart failure. The laboratory workup reported hemoglobin at $9.2 \mathrm{~g} / \mathrm{dL}$ (normal range: $12-18 \mathrm{~g} / \mathrm{dL}$ ), platelet at $121 \mathrm{G} / \mathrm{L}$ (normal range: $150-450 \mathrm{G} / \mathrm{L}$ ), total bilirubin at $140 \mu \mathrm{mol} / \mathrm{L}$ (normal range: $<21 \mu \mathrm{mol} / \mathrm{L}$ ) with conjugated bilirubin at $55 \mu \mathrm{mol} / \mathrm{L}$ (normal range: $<5 \mu \mathrm{mol} / \mathrm{L}$ ), alanine aminotransferase at $90 \mathrm{U} / \mathrm{L}$ (normal range: $>45 \mathrm{U} / \mathrm{L}$ ), aspartate aminotransferase at $67 \mathrm{U} / \mathrm{L}$ (normal range: $<31 \mathrm{U} / \mathrm{L}$ ), gamma-glutamyl transpeptidase at $40 \mathrm{U} / \mathrm{L}$ (normal range: 9-39 U/L), alkaline phosphatase at 460 U/L (normal range: 64-306 U/L), prothrombin level at $31.4 \%$ (normal range: $70-100 \%$ ), C-reactive protein at 10, $9 \mathrm{mg} / \mathrm{L}$ (normal range: < $10 \mathrm{mg} / \mathrm{L}$ ), albumin $16 \mathrm{~g} / \mathrm{L}$ (normal range: $35-53 \mathrm{~g} / \mathrm{L}$ ), ferritin $9.28 \mathrm{ng} / \mathrm{mL}$ (normal range: $9.3-159 \mathrm{ng} / \mathrm{mL}$ ), creatinine $78 \mu \mathrm{mol} / \mathrm{L}$ (normal range: $45-105 \mu \mathrm{mol} / \mathrm{L}$ ), and protein in fluid $6 \mathrm{~g} / \mathrm{L}$. Serum protein electrophoresis reported a beta-gamma block and absence of hypergammaglobulinemia. Hepatitis $\mathrm{B}$ and $\mathrm{C}$ serologies were negative. The abdominal Doppler ultrasound of 08/18/2021 showed a large cystic mass, rounded, well limited in the sub-hepatic area, in communication with the common bile duct (Fig. 1). She had reported dilatation of the main bile duct, a dysmorphic liver associated with signs of portal hypertension with re-permeabilization of the umbilical vein, ascites, and splenomegaly. The abdominal and pelvic CT scan of August 202021 showed a large intraabdominal cystic mass at the common bile duct classified as TODANI type IVA and a dysmorphic liver with cirrhotic appearance (Fig. 2). The upper gastrointestinal endoscopy showed an absence of esophageal varices (Fig. 3). The diagnosis of a type IVA choledochal cyst at the stage of decompensated cirrhosis, Child-Pugh C12 was retained. Endoscopic stenting was indicated due to the severity of the liver damage but was not available in Madagascar. A collegial decision (hepato-gastroenterologists and visceral surgeons) had opted only for management of cirrhotic decompensation in view of the patient's ineligibility for surgery. The patient had a good evolution under diuretic (Aldactone ${ }^{\circledR} 75 \mathrm{mg}$ /day) with decrease of abdominal perimeter and weight loss.

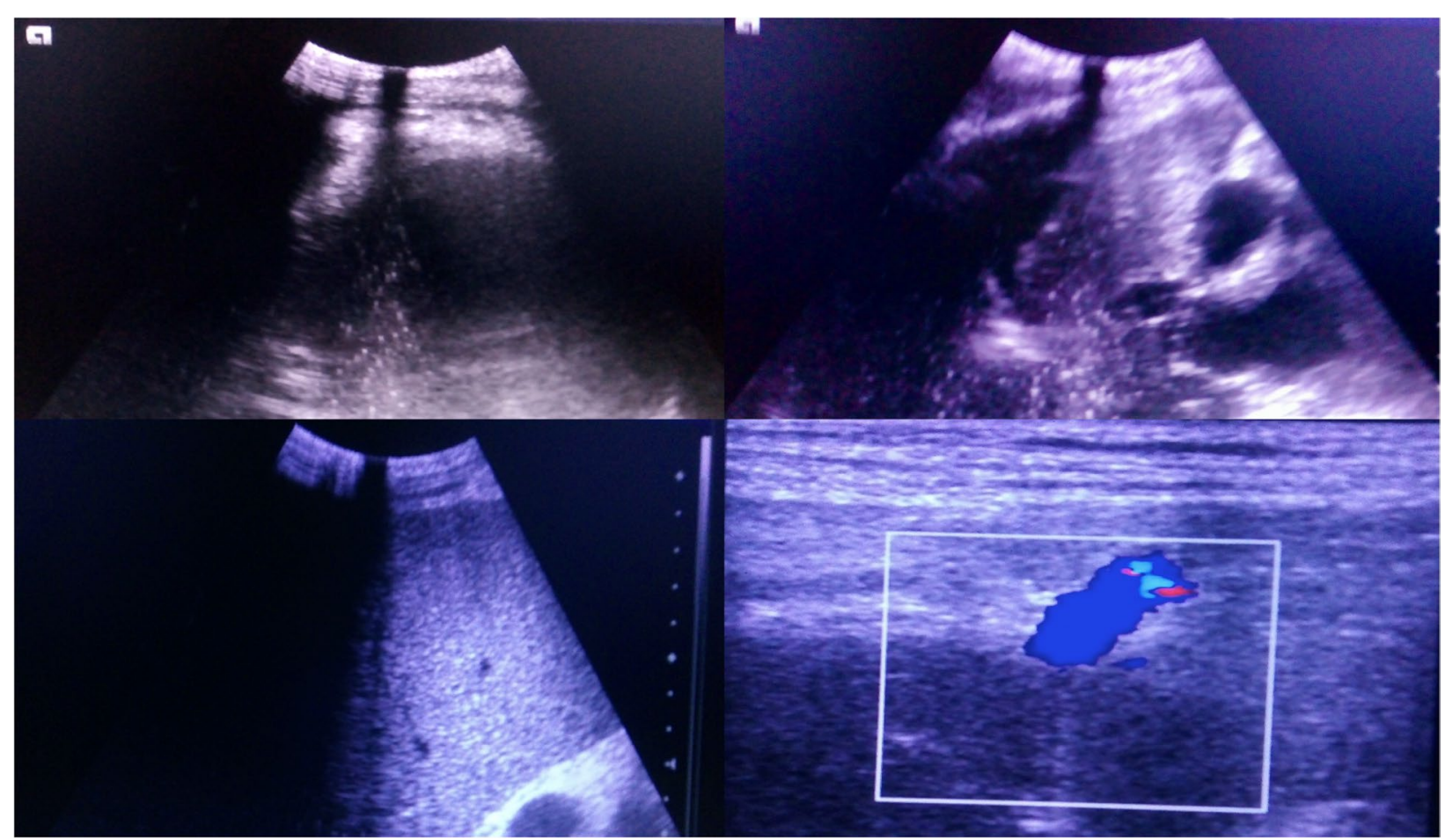

Fig. 1 Abdominal ultrasound showing a large, rounded, well-limited cystic mass in communication with the common bile duct 

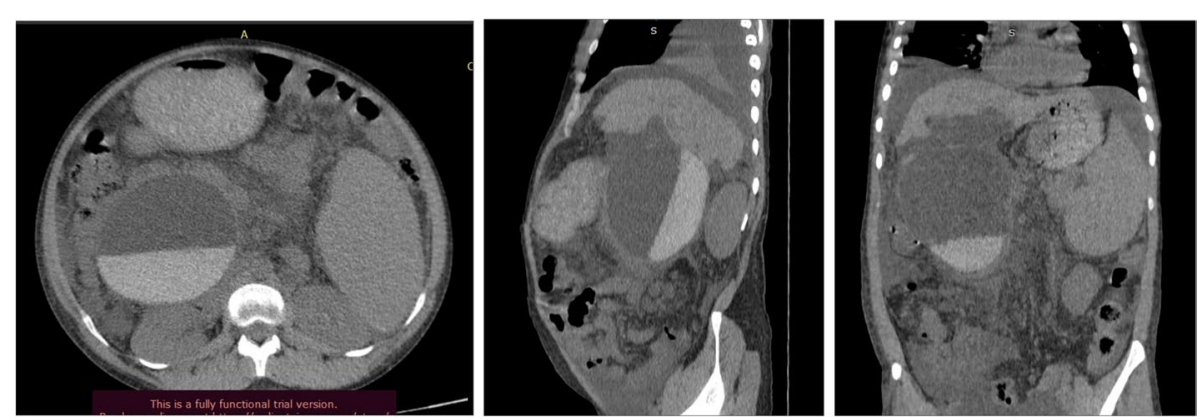

Fig. 2 Abdominal CT scan showing a large intra-abdominal cystic mass at the common bile duct classified as TODANI type IVA and a dysmorphic liver of cirrhotic appearance

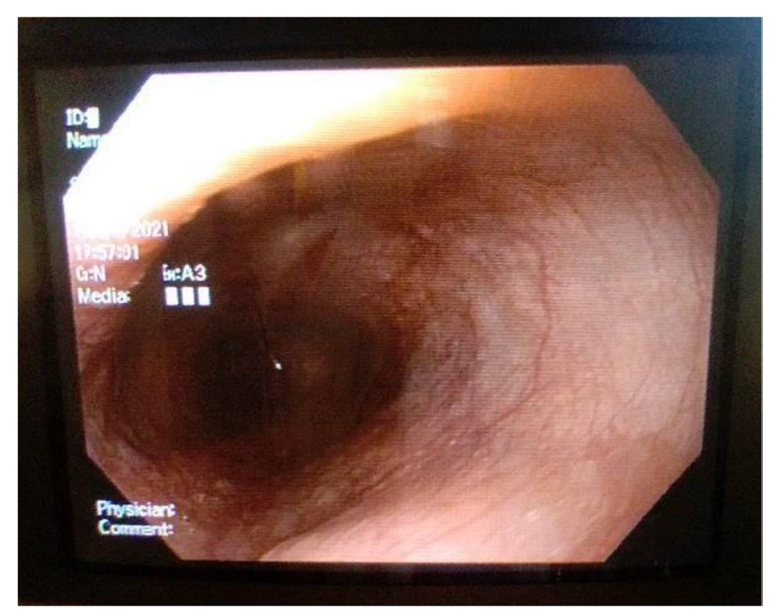

Fig. 3 Upper gastrointestinal endoscopy showed an absence of esophageal varices

\section{Discussion and conclusion}

We report the first case of Choledochal cyst (CDC) in Madagascar. Choledochal cysts are rarely reported in sub-Saharan Africa. In Nigeria, Akinyinka et al. [8] reported only 3 cases in 18 years. Although CDCs are congenital anomalies, $20 \%$ of patients are diagnosed in adulthood. CDC is more frequently observed in females (1 male/4 females), as in our case. Our patient had a CDC type IVA. Type IVA was recognized as the most frequent in adults and their prevalence is 2 to $39 \%$ [4]. In a large US series, the prevalence of type IVA CDC ranged from 14 to $60 \%$ [4]. Secondary biliary cirrhosis (SBC) remains a late complication of CDCs. It is observed in $15 \%$ of adults and typically in the background of type IV and V CDCs. Cirrhosis is rarely the circumstance of discovery of the disease [5-7]. Several situations may explain the discovery of these CDCs at the stage of complications in adults. CDCs are only symptomatic in $20-30 \%$ of cases [9]. In addition, the diagnosis of CDCs is often delayed in adults due to nonspecific clinical symptoms or symptoms masked by secondary hepatobiliary diseases [10]. Delays in diagnosis and treatment can often last for years, leading to an increased risk of complications such as SBC, PHT, and malignancy [10].

Several radiological examinations can be used to evaluate CDC. Ultrasound remains a good screening tool to assess bile duct dilation. CT scan is widely used to rule out other etiologies of bile duct dilation. However, ultrasonography and CT scan do not provide an optimal evaluation of the biliary tree; hence, the need for cholangiography. Magnetic resonance cholangiopancreatography (MRCP) is currently considered the gold standard for the initial evaluation and diagnosis of CDC. Endoscopic retrograde cholangiopancreatography (ERCP) and percutaneous transhepatic cholangiography are invasive forms of cholangiography that may still be necessary to confirm the diagnosis and demonstrate the abnormality of the pancreaticobiliary junction (APBJ) [1, 4-7]. Our patient had benefited only from ultrasound and CT scan to retain the diagnosis of $\mathrm{CDC}$. MRCP and cholangiography were indicated in our patient to evaluate the biliary tree and to look for an APBJ, but these explorations are currently not available in Madagascar.

The management of CDC with cirrhosis depends on the Child-Pugh score, the presence of portal thrombosis, and amount of collaterals around the cyst [5-7]. Although decompression by Roux-enY drainage can result in adequate long-term functional improvement in $60-70 \%$ of cases, excision and hepaticojejunostomy is the treatment of choice [5]. Surgical treatment requires preoperative preparation, including correction of the coagulation status, improvement of albumin levels, and control of ascites and varices. Endoscopic stent drainage can be used as a temporary measure in patients who are not suitable for surgery. Therefore, patients may be considered for definitive surgical treatment once endoscopic stenting has improved liver function and reduced surgical risk in these patients [5-7]. Saluja et al. [5] had 


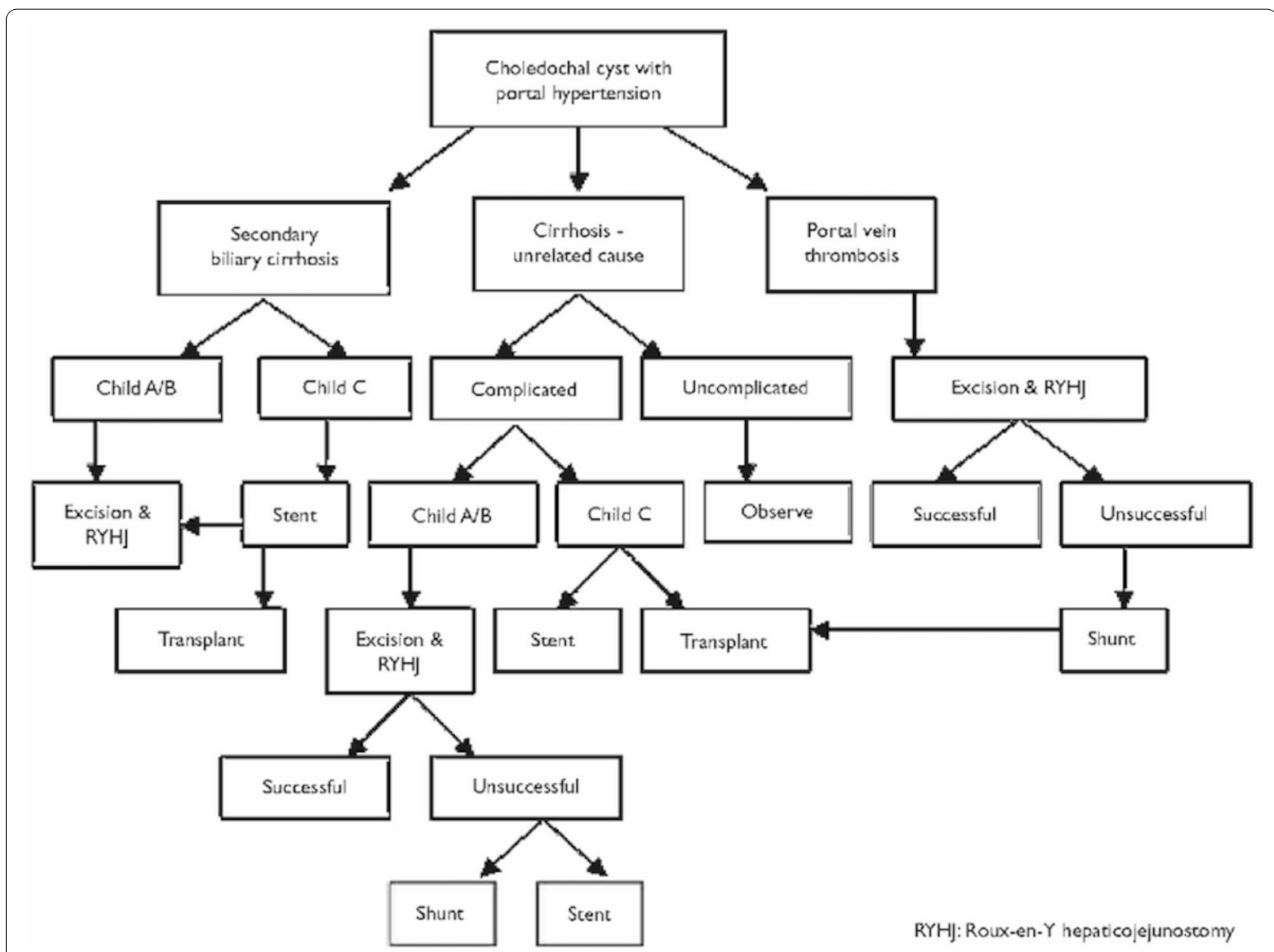

Fig. 4 Algorithm for management of choledochal cyst with portal hypertension. Saluja SS, Mishra PK, Sharma BC, Narang P. Management of choledochal cyst with portal hypertension. Singapore Med J. 2011; 52(12): e239

proposed an algorithm for the management of CDC in patients with cirrhosis and portal hypertension (Fig. 4). Liver transplantation remains the treatment of choice for patients with Child-Pugh C cirrhosis [5-7]. The conservative treatment with endoscopic stent drainage was indicated in our patient but is not available in Madagascar. In countries where therapeutic investigations are limited like Madagascar, the management of CDC with SBC with PTH will be discussed on a case-by-case basis, such as the case of our patient.

In conclusion, $\mathrm{SBC}$ with $\mathrm{PTH}$ constitutes a rare evolutionary complication of CDC. CDCs should be detected in childhood to benefit from adequate surgical management and reduce the occurrence of complications. Management should be multidisciplinary and discussed on a case-by-case basis depending on the severity of the liver damage. Endoscopic stenting may be considered as a temporary measure in high-risk cases.

\section{Abbreviations}

CDC: Choledochal cyst; SBC: Secondary biliary cirrhosis; PTH: Portal hypertension; APBJ: Abnormality of the pancreaticobiliary junction; MRCP: Magnetic resonance cholangiopancreatography; ERCP: Endoscopic retrograde cholangiopancreatography.

\section{Acknowledgements}

We would like to thank the teams of the Department of Gastroenterology, University Hospital Joseph Raseta Befelatanana for taking care of the patient and the radiology team of the University Hospital Joseph Ravoahangy Andrianavalona for the interpretation of radiological images.

\section{Authors' contributions}

CIR collected data, performed critical analysis, and wrote the manuscript. ALRR performed critical analysis and participated in the redaction of the manuscript. SMR collected data performed critical analysis. NHR, DHHL, SM, LHNONR, THR, SHR, and RMR critically reviewed the manuscript. All authors read and approved the final manuscript.

Availability of data and materials

Data are available on request from the corresponding author. 


\section{Declarations}

Ethics approval and consent participate

Not applicable.

\section{Consent for publication}

Informed consent was obtained from the patient. A signed consent form authorizing the publication is available and included in the patient's chart.

\section{Competing interests}

All authors declare that they have no competing interests.

\section{Author details}

${ }^{1}$ Unity of Gastroenterology, University Hospital Joseph Raseta Befelatanana, Antananarivo, Madagascar. ${ }^{2}$ Unity of Radiology, University Hospital Joseph Ravoahangy Andrianavalona, Antananarivo, Madagascar. ${ }^{3}$ Unity of Hepato-Gastroenterology, University Hospital Andrainjato, Fianarantsoa, Madagascar.

Received: 23 November 2021 Accepted: 30 December 2021

Published online: 21 January 2022

\section{References}

1. Soares KC, Arnaoutakis DJ, Kamel I et al (2014) Choledochal cysts: presentation, clinical differentiation, and management. J Am Coll Surg 219(9):1167-1180

2. He Y, Yu Z, Chen W (2020) Type IV choledochal cyst with polycystic kidney disease: a case report. BMC Gastroenterol 20:306

3. Gupta N, Gupta V, Noushif M, Singh SK, Kumar P, Chandra A (2015) Unusual presentations of choledochal cyst: case series and review of literature. Indian J Surg 77(3):S1318-S1322

4. Wiseman K, Buczkowski AK, Chung SW, Francoeur J, Schaeffer D, Scudamore CH (2005) Epidemiology, presentation, diagnosis, and outcomes of choledochal cysts in adult in an urban environment. Am J Surg 189:527-531

5. Saluja SS, Mishra PK, Sharma BC, Narang P (2011) Management of choledochal cyst with portal hypertension. Singap Med J 52(12):e239

6. Edil BH, Olino K, Cameron JL (2009) The current management of choledochal cysts. Adv Surg 43:221-232

7. Lewis VA, Adam SZ, Nikolaidis P, Wood C, Wu JG, Yaghmai V, Miller FH (2015) Imaging of choledochal cysts. Abdom Imaging 40(6):1567-1580

8. Akinyinka OO, Une Falade G, Akinbami FO et al (2005) Choledochal cysts in African infants : a report of 3 cases and a review of the literature. Trop Gastroenterol 26(1):34-36

9. Singham J, Yoshida EM, Scrudamore CH (2009) Choledochal cysts: part 2 of 3: Diagnosis. Can J Surg 52:506-511

10. Lee HK, Park SJ, Yi BH, Lee AL, Moon JH, Chang YW (2009) Imaging features of adult choledochal cysts: a pictorial review. Korean J Radiol 10:71-80

\section{Publisher's Note}

Springer Nature remains neutral with regard to jurisdictional claims in published maps and institutional affiliations.

\section{Submit your manuscript to a SpringerOpen ${ }^{\circ}$ journal and benefit from:}

- Convenient online submission

- Rigorous peer review

- Open access: articles freely available online

- High visibility within the field

- Retaining the copyright to your article 